\title{
EGF Regulates Early Embryonic Mouse Gut Development in Chemically Defined Organ Culture
}

\author{
GLENN DUH, NARUAKI MOURI, DAVID WARBURTON, AND DAN W. THOMAS
}

\begin{abstract}
Division of Gastroenterology and Nutrition, Department of Pediatrics [G.D., D.W.T.] and Department of Surgery [N.M., D.W.], Childrens Hospital Los Angeles, University of Southern California Keck School of Medicine, Los Angeles, California 90027, U.S.A.; Center for Craniofacial Molecular Biology, University of Southern California School of Dentistry, Los Angeles, California 90027, U.S.A. [N.M., D.W.]; and Developmental Biology Program, Childrens Hospital Los Angeles Research Institute, Los Angeles, California 90027, U.S.A. [D.W.] Current affiliation [N.M.]: $2^{\text {nd }}$ Department of Surgery, Yamanashi University, Yamanashi 409-3898, Japan
\end{abstract}

\section{ABSTRACT}

The profound intestinal epithelial defects in the newborn epidermal growth factor receptor (EGFR) knockout mouse suggests that EGFR signaling plays important roles in embryonic gut development. Herein, we further elucidated the function of EGFR signaling on early embryonic gut development by comparing the effects of $1-10 \mathrm{ng} / \mathrm{mL}$ of exogenous epidermal growth factor (EGF) or 10-25 $\mu \mathrm{M}$ of the tyrphostin 3,4,5 trihydroxybenzene malononitrile, a specific inhibitor of EGFR tyrosine kinase, on intact E12 Swiss-Webster mouse midgut grown in chemically defined organ culture using Fitton-Jackson BGJb medium for 4 or $6 \mathrm{~d}$. Intestinal development during culture was assayed by morphometry, histology, reverse transcription/ competitive PCR for villin and intestinal fatty acid binding protein mRNA, and immunohistochemistry for epithelial proliferative markers. During organ culture, control specimens grew in length, developed smooth muscle, simple columnar epithelial and goblet cell phenotypes, showed early villus formation in the proximal intestine, and increased expression of villin and intestinal fatty acid binding protein mRNA. EGF failed to significantly alter small intestinal lengthening, whereas EGF $10 \mathrm{ng} / \mathrm{mL}$ inhibited colonic length growth. Tyrphostin $25 \mu \mathrm{M}$ resulted in regional losses of stromal and smooth muscle cells in the small intestine and absent colonic goblet cells. In controls, cellular proliferation initially occurred throughout the small intestinal epithelium but became increasingly localized to the intervillus crypt regions. This sequestration of epithelial proliferation into crypts was much more apparent in EGF-treated versus tyrphostin-treated specimens. EGFR activation, therefore, appears to accelerate the maturation rate of goblet cells and the differential crypt/villus proliferation pattern in early embryonic mouse gut. (Pediatr Res 48: 794-802, 2000)
BrdU, bromodeoxyuridine
EGF, epidermal growth factor
EGFR, epidermal growth factor receptor
HBSS, Hanks' balanced salt solution
iFABP, intestinal fatty acid binding protein
PCNA, proliferating cell nuclear antigen
RT, reverse transcription

The EGFR knockout (-/-) mouse that was reported by Miettinen et al. (1) exhibits delayed maturation of the intestinal epithelium in utero compared with its wild-type or heterozygous littermates and, at birth, has abnormally shortened small intestinal villi and flattened colonic mucosa. Postnatally, these animals are highly prone to intestinal epithelial damage and develop features that are similar to human necrotizing enterocolitis within the first

Received November 18, 1999; accepted July 11, 2000.

Correspondence and reprint requests: Glenn Duh, M.D., Division of Gastroenterology and Nutrition, Childrens Hospital Los Angeles, 4650 Sunset Blvd., Mailstop 78, Los Angeles, CA 90027, U.S.A.

Supported by the Childrens Hospital Los Angeles Research Institute and the Good Hope Medical Foundation. few days of life. Because the gut epithelium of the $\mathrm{EGFR}^{-/ /}$mouse appears to be immature and human necrotizing enterocolitis is associated with premature birth (2), EGFR signaling appears to play an important role in embryonic gut development by promoting gut epithelial maturation.

The role of EGFR signaling in promoting gut maturation has also been suggested by in vivo studies in which animals were given exogenous EGF (3-5). However, because EGFR signaling also affects the development of other fetal organs that include the liver and pancreas $(1,6,7)$, it is not clear whether observations on these experimental models represent endogenous effects of EGFR signaling in the gut or results that are secondary to EGFR signaling in other organs. 
The chemically defined organ culture model of embryonic gut has the advantage that endogenous determinants of gut development can be studied in isolation under the native cellular and structural environment of the tissue, and the local chemical environment of the tissue can be precisely manipulated. Such organ culture approaches have been used to successfully assay specific mechanisms by which EGFR signaling regulates embryonic gut epithelial maturation (8-15). In the mature gut, EGF both acts as a mitogen and increases the expression of mucosal digestive enzymes in differentiated enterocytes (16-18). In contrast, previous organ culture studies on the effects of exogenous EGF on the developmental characteristics of embryonic mouse, rat, and human gut showed that the results appeared to be influenced by the species, anatomical region, and developmental stage of the regions that were studied. In organ culture of mouse small intestine, exogenous EGF had no significant effect on the DNA content at E17 or postnatal d 8, did not affect brush-border enzyme expression at postnatal $\mathrm{d} 8$, but increased the expression of several brushborder enzymes and rough endoplasmic reticulum density at E17 (8-11). On the other hand, EGF markedly increased DNA synthesis in the late gestational and suckling rat intestine (12), and, in early gestation human gut, exogenous EGF markedly decreased DNA synthesis and brush-border enzyme expression in the small intestine and colon $(13,14)$ but increased DNA and glycoprotein synthesis in the stomach (15).

The wide repertoire of EGF-mediated effects suggests that the developing gut's response to EGF varies along its spatial and temporal axes and varies between species. It is also possible that some of the observed responses may be due to the use of supraphysiologic EGF concentrations. Most of these previous studies used EGF at concentrations of 50 to 500 $\mathrm{ng} / \mathrm{mL}$, which are similar to those of early mouse milk (19). However, such concentrations may be excessive for organ culture of embryonic gut, because EGF is present at much lower levels in amniotic fluid and in embryonic tissue $(20,21)$.

Despite the many organ culture studies noted above, the function of EGF in early embryonic gut development has not yet been fully characterized. This study seeks to further determine the function of EGFR signaling in the early embryonic mouse gut. We first developed and characterized an in vitro model of early embryonic gut development using serumless chemically defined organ culture of E12 mouse gut. This model was then used to study the effects of exogenous EGF and/or the tyrphostin 3,4,5 trihydroxybenzene malononitrile, which specifically inhibits EGFR autophosphorylation (22), on the in vitro development of E12 mouse gut. By stimulating EGFR signaling, we expected that exogenous EGF would accelerate early embryonic gut maturation in vitro. Conversely, tyrphostin should interfere with early embryonic gut maturation and cause E12 mouse gut cultured in vitro to develop phenotypes that are similar to the embryonic EGFR ${ }^{-/-}$mouse gut.

\section{METHODS}

The present study was reviewed and approved by our institutional Animal Care Committee.
Mouse embryos. Timed-pregnant female Swiss-Webster mice were killed at E12, and the embryos were removed from the uterine decidua, washed in HBSS, and developmentally staged by external features according to Theiler (23). Gut segments of E14-E16 embryos and the killed adult females were used for comparison.

Preparation of organ cultures. By use of dissecting microscope and microphthalmic surgical instruments, gut primordia spanning from the duodenojejunal junction to the midcolon were dissected intact from Theiler stage 20 (E12) embryos. Organ cultures were performed according to our modification of the method of Warburton et al. (24). Briefly, the tissues were placed individually on Millipore filter disks that were supported by a stainless steel mesh at the air-medium interface of the organ culture dish (up to 10 explants per dish). The explants were cultured in Fitton-Jackson modification BGJb medium (Life Technologies, Grand Island, NY, U.S.A.) containing $0.1 \mathrm{mg} / \mathrm{mL}$ ascorbic acid and penicillin/streptomycin (100 U penicillin $/ \mathrm{mL}$ ), $5 \% \mathrm{CO}_{2}$ and $95 \%$ air at $1 \mathrm{~atm}$, and $37^{\circ} \mathrm{C}$ for up to $6 \mathrm{~d}$ with medium changes every $2 \mathrm{~d}$.

Morphometry. Cultured tissues were photographed at $\times 25$ magnification on d $0,2,4,5$, and/or 6 of organ culture, up to the time of tissue harvest. Digitalized photographs of the transilluminated specimens were used to obtain contour line tracings of the cultured gut specimens for length analysis. In addition, intestinal walls were clearly delineated in these transilluminated images by contrast from intraluminal fluid, and intestinal wall thicknesses (the combined thickness of the mucosal and smooth muscle layers) were measured at the distal third of the small intestine. Measurements were obtained by computer-assisted image analysis using Scion Image (Scion Corp., Frederick, MD, U.S.A.), a PC version of the public domain National Institutes of Health image analysis program. Lengths were also measured in comparable segments of E14E16 gut for comparison.

Tissue fixation. Tissues were fixed in either Carnoy's fixative ( $10 \%$ glacial acetic acid, $30 \%$ chloroform, $60 \%$ ethanol) or $4 \%$ paraformaldehyde at room temperature for $1 \mathrm{~h}$ and processed for embedding in paraffin. The paraffin blocks were stored at $4^{\circ} \mathrm{C}$ until sectioning.

Histology. Five-micrometer sections of paraffin-embedded tissues were mounted on Histogrip (Zymed Laboratories, San Francisco, CA, U.S.A.) coated glass slides and processed for staining with hematoxylin/eosin or alcian blue/nuclear fast red. The mucus of goblet cells stains alcian blue-positive.

Immunohistochemistry. For immunohistologic detection of S-phase cells, the cultured explants were given a 2-h pulse of BrdU $100 \mu \mathrm{g} / \mathrm{mL}$ just before harvest on $\mathrm{d} 4$ or 6 and immediately washed in PBS. The tissues were then fixed in Carnoy's fixative for $1 \mathrm{~h}$, processed for embedding in paraffin blocks, and sliced into 5- $\mu \mathrm{m}$ thickness. BrdU immunostaining was performed according to instructions using the Zymed BrdU kit, which contains a conjugated anti-BrdU MAb. PCNA expression was assayed by immunostaining of tissue sections with the Zymed Histomouse SP kit and an anti-PCNA MAb (DAKO, Carpinteria, CA, U.S.A.) that was used at 1:25 dilution with a 60-min incubation time. 
RT/competitive PCR. Gut-specific epithelial lineage differentiation of E12 mouse gut during organ culture was assayed by performing RT/competitive PCR for villin and iFABP mRNA. Total RNA was extracted from dissected E12 mouse gut that was cultured for 0 to $7 \mathrm{~d}$ and on E16 mouse intestines for comparison using the Micro Scale Rapid Total RNA Isolation Kit (5 Prime -> 3 Prime, Inc., Boulder, CO, U.S.A.). PCR primers were synthesized by Life Technologies (Grand Island, NY, U.S.A.), and the remaining RT/PCR components were purchased from Promega Corp. (Madison, WI, U.S.A.). RT was performed on approximately $1 \mu \mathrm{g}$ of total RNA per reaction in $20-\mu \mathrm{L}$ volumes using oligo-dT (15) primer and M-MLV reverse transcriptase.

Competitive PCR for iFABP and villin mRNA was performed on equivalent amounts of reverse-transcribed cDNA using $\beta$-actin mRNA levels as internal controls. The murine $\beta$-actin primers and competitor were generously provided by Jingsong Zhao (Center for Craniofacial Molecular Biology, University of Southern California School of Dentistry, Los Angeles, CA, U.S.A.) and their preparation and characterization were described in Zhao and Nishimoto (25). The amplified $\beta$-actin cDNA and competitor have sizes of 324 and $430 \mathrm{bp}$, respectively, share identical flanking primer sequences, and have unrelated core sequences. Approximately $30 \mathrm{ng}$ of cDNA was coamplified with $0.25 \mathrm{pg}$ of $\beta$-actin competitor in $50-\mu \mathrm{L}$ reactions using Taq DNA polymerase $1.25 \mathrm{U}$, dATP, dTTP, dCTP, and dGTP $200 \mathrm{nM}$ each, primers $500 \mathrm{nM}$ each, and $\mathrm{Mg}$ $2.5 \mathrm{mM}$. A RoboCycler (Stratagene, La Jolla, CA, U.S.A.) was used to perform 35 cycles of amplification with 1-min steps of 93,62 , and $72^{\circ} \mathrm{C}$ per cycle except for an initial 3-min strand separation step at $93^{\circ} \mathrm{C}$ and a final 5 -min extension step at $72^{\circ} \mathrm{C}$. Densitometry was performed on digitized $2 \%$ agarose gel images using Scion Image, and $\beta$-actin mRNA levels were determined by comparing ratios of $\beta$-actin/competitor cDNA band intensities with a standard plot. The standard plot was generated by coamplifying a fixed $0.25 \mathrm{pg}$ of competitor with serial dilutions of $\beta$-actin cDNA, which was produced by RT/PCR of mouse intestinal mRNA, and purified using the Promega Wizard PCR Preps DNA Purification System.

The primer sequences for iFABP were CTA GAG ACA CAC ACA GCT GAG ATC ATG G and GCA ATC AGC TCC TTT CCA TTG TCT ACA C, which yield a 338-bp amplification product that spans two introns. Its competitor is a 301-bp amplification product that was generated by attaching iFABP primer sequences to a 245 -bp $\beta$-actin cDNA core using hybrid primers that contain both flanking iFABP and internal $\beta$-actin sequences. Competitive PCR for iFABP was performed by amplifying cDNA standardized to $0.125 \mathrm{pg}$ of $\beta$-actin along with a fixed $20 \mathrm{fg}$ of competitor per reaction. Thirty-two cycles of amplification were performed using 35-s steps of 94,62 , and $72^{\circ} \mathrm{C}$ per cycle except for an initial 3-min strand separation step at $94^{\circ} \mathrm{C}$ and a final 5-min extension step at $72^{\circ} \mathrm{C}$. Quantitative determination of iFABP mRNA was carried out similarly to that for $\beta$-actin.

The primer sequences for villin were CAG TGG GGA TGA GAG GGA GA and CCT GCT TCA CCA CGA TGA TA, which yields a 416 -bp product. The villin competitor was produced using the same $\beta$-actin core as for the iFABP com- petitor and has a length of $285 \mathrm{bp}$. For competitive PCR, 36 cycles of amplification were performed on cDNA standardized to $0.125 \mathrm{pg}$ of $\beta$-actin mRNA along with $10 \mathrm{fg}$ of villin competitor per reaction, using the same reaction times and temperatures as for iFABP.

The number of PCR cycles used for each competitive PCR was optimized to ensure that the assay was within the linear range, and linear relationships between the cDNA/competitor ratio and the densitometric ratios of their amplification products were preserved in the standard plots.

EGF and tyrphostin. Stock solutions of receptor-grade murine EGF $(0.5 \mu \mathrm{g} / \mu \mathrm{L})$ and the tyrphostin 3,4,5 trihydroxybenzene malononitrile $(5 \mathrm{mM})$ were prepared by mixing in HBSS and DMSO, respectively, aliquoted, stored at $-20^{\circ} \mathrm{C}$, and used within 2 mo. Both EGF and tyrphostin were purchased from Life Technologies, Grand Island, NY, U.S.A. The tyrphostin used has an $\mathrm{IC}_{50}$ of $15 \mu \mathrm{M}$ for EGFR autophosphorylation and is a specific inhibitor of EGFR tyrosine kinase that does not affect EGF-independent cell growth in cell culture (22). Effects of exogenous EGF on in vitro embryonic gut development were initially determined by culturing E12 gut explants with EGF 1 or $10 \mathrm{ng} / \mathrm{mL}$ for 4 or $6 \mathrm{~d}$, with medium changes every $2 \mathrm{~d}$, and comparing them to controls $(0 \mathrm{ng} / \mathrm{mL})$. Effects of EGFR signaling on E12 gut explants were further studied by culturing the specimens in medium containing either tyrphostin $10 \mu \mathrm{M}$, tyrphostin $25 \mu \mathrm{M}$, EGF $10 \mathrm{ng} / \mathrm{mL}$, tyrphostin $25 \mu \mathrm{M}$ + EGF $10 \mathrm{ng} / \mathrm{mL}$, or controls for 4 or $6 \mathrm{~d}$. Because media that included tyrphostin $25 \mu \mathrm{M}$ contained $0.5 \% \mathrm{vol} / \mathrm{vol}$ of the DMSO vehicle, additional DMSO was added to groups that contained no tyrphostin or tyrphostin $10 \mu \mathrm{M}$ to achieve a fixed $0.5 \% \mathrm{vol} / \mathrm{vol}$ concentration of DMSO for all groups, to account for any possible effects of DMSO on in vitro gut development.

Statistical analyses. Unless otherwise indicated, average values are expressed as mean $+/$ - SEM, and analyses of significance were tested by 1-way ANOVA with posttesting when indicated with the Tukey-Kramer multiple comparisons test. Raw data from RT/competitive PCR values were transformed logarithmically to obtain a more normal distribution before statistical analyses. A $p$ value $<0.05$ was accepted as statistically significant.

\section{RESULTS}

E12 mouse gut increased in length and developed differentiated cell phenotypes during in vitro organ culture. E12 gut explants grew linearly in length during the first $6 \mathrm{~d}$ of in vitro organ culture, with length growth occurring mostly in the small intestine (Fig. 1). This length change is, however, markedly less than that which occurred during in vivo growth. Rhythmic contractile activity in the small intestine appeared by 4 to $5 \mathrm{~d}$ of culture. Anatomic regions that were identifiable at E12 (small intestine, cecum/appendix, and colon) remained distinct throughout the organ culture (Fig. 2, $A$ and $B$ ). Numerous villus-like epithelial buds could be seen through the semitransparent proximal small intestine after as early as $4 \mathrm{~d}$ and in all specimens by $6 \mathrm{~d}$ of culture.

Histologically, E12 mouse gut consists of a single-cell layer tube of endoderm that is surrounded by mesenchyme. In the 


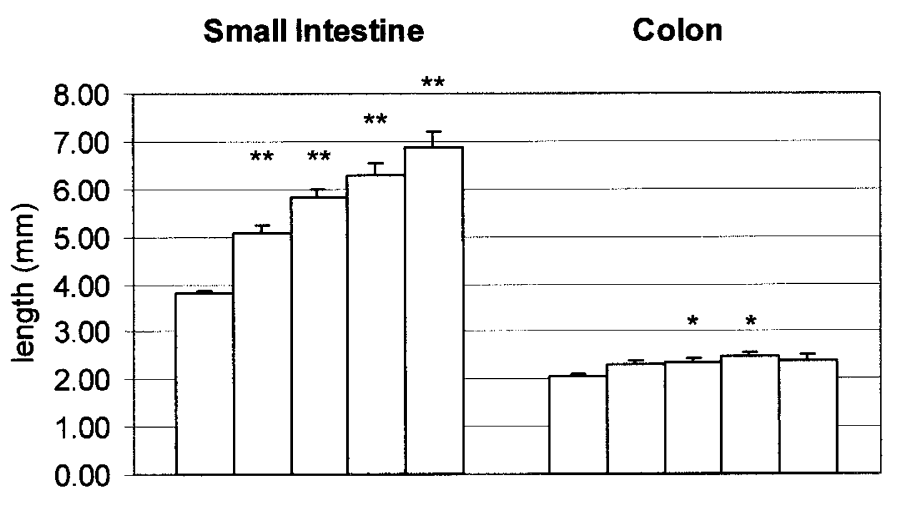

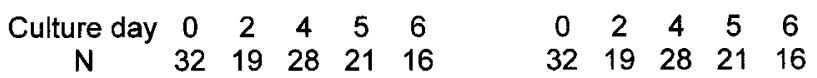

Figure 1. E12 mouse gut increased differentially in length during serumless chemically defined organ culture. Results are shown as mean length $+/$ - SEM, with paired comparisons with d $0 .{ }^{*} p<0.05 ;{ }^{* *} p<0.001$

proximal small intestine, differentiating columnar epithelial cells with basolateral nuclear polarity appeared, and the epithelial cells were organized into numerous villus-like protuberances during organ culture (Fig. 2, $C$ and $D$ ). A single layer of polarized columnar epithelium, in contrast, characterized the distal small intestine during this period. In comparison, rudimentary villi initially appeared throughout the embryonic mouse small intestine in vivo at E16.

A loosely organized layer of subepithelial mesenchymal cells and matrix appeared throughout the cultured gut, which were in turn surrounded by well-developed layers of smooth muscle. The cecum and appendix became dilated and easily identifiable. The colonic epithelium, unlike the small intestine, was stratified and appeared relatively unorganized except at the basal layer where nuclear polarity was predominant. Numerous alcian blue-positive cells with goblet cell-like morphology appeared in the colon but not in the cecum or appendix between 5 to $6 \mathrm{~d}$ of culture (Fig. 2, $C$ and E). In vivo, alcian blue-positive cells first appear in the colon at E16.

iFABP and villin mRNA expression increased in E12 mouse gut during organ culture. iFABP mRNA levels were low at E12 (2.4 fg per $0.125 \mathrm{pg}$ of $\beta$-actin mRNA) and increased significantly after 4 to $7 \mathrm{~d}$ of organ culture (Fig. 3, $A-D)$. After logarithmic transformation, iFABP levels increased by an average of approximately 100 -fold $(p<0.005)$, whereas the level in E16 intestines in vivo was $>5,000$ times greater than in E12 gut. On the other hand, gut villin mRNA levels increased 5- to 17-fold after 4 to $7 \mathrm{~d}$ of organ culture and were similar to those of E16 intestines in vivo. Neither villin nor iFABP mRNA expression appeared to be significantly altered by exogenous EGF or tyrphostin in this study (Fig. 3, E and $F$ ).

E12 mouse gut showed temporally and regionally distinct patterns of proliferative activity in vitro. In the small intestine, epithelial BrdU incorporation and/or PCNA expression were noted to be generally higher at $4 \mathrm{~d}$ than at $6 \mathrm{~d}$ of organ culture. Proliferative activity occurred in most of the intervillus epithelial cells but only in a small proportion of epithelial cells within the villus-like structures (Fig. $2 F$ ). This pattern of epithelial proliferation became especially distinct after $6 \mathrm{~d}$ of organ culture, when BrdU incorporation became essentially absent in the villus-like structures (not shown). In contrast, epithelial proliferation in the colon was greatest at $6 \mathrm{~d}$ of organ culture and occurred predominantly at the epithelial-mesenchymal interface (not shown).

Exogenous EGF and tyrphostin differentially altered small intestinal and colonic length growth of E12 mouse gut in vitro. In preliminary organ culture experiments with exogenous EGF, EGF did not significantly affect the rate of small intestinal length growth compared with controls during organ culture (Fig. $4 A$ ). In contrast, Figure $4 B$ shows that EGF 10 $\mathrm{ng} / \mathrm{mL}$ inhibited colonic length growth compared with controls ( $p<0.05, t$ test for both comparisons). Villi were present in $55.2 \%$ of the controls compared with 71.4 and $69.0 \%$ of specimens that were grown in EGF 1 and $10 \mathrm{ng} / \mathrm{mL}$, respectively, at $4 \mathrm{~d}$ of culture (not statistically significant by $\chi^{2}$ ). All specimens developed villi by $6 \mathrm{~d}$. Finally, both EGF 1 and 10 $\mathrm{ng} / \mathrm{mL}$ increased small intestinal wall thickness after $6 \mathrm{~d}$ (Fig. $4 C$ ).

The role of EGFR signaling on embryonic gut growth was further studied by culturing E12 mouse gut in the presence of exogenous EGF and/or tyrphostin. Both specimens that were cultured with tyrphostin $25 \mu \mathrm{M}$ alone and those grown in both tyrphostin $25 \mu \mathrm{M}$ and EGF $10 \mathrm{ng} / \mathrm{mL}$ showed significantly decreased small intestinal length growth compared with specimens that were cultured with EGF $10 \mathrm{ng} / \mathrm{mL}$ (Fig. 4D). In contrast, tyrphostin did not significantly affect colonic growth.

EGF and tyrphostin altered histologic development of E12 mouse gut during organ culture. Specimens that were cultured in exogenous EGF and/or tyrphostin all developed abundant villus-like epithelial structures in the proximal intestine. However, tyrphostin $25 \mu \mathrm{M}$ was associated with defects at the antimesenteric aspects of the small intestine that included marked losses of stromal and smooth muscle cells, flattening of epithelial cells, and wall herniation (Fig. 2, $H$ and $I$ ). Exogenous EGF appeared to partially ameliorate these defects. Moreover, goblet cells were absent at $6 \mathrm{~d}$ of culture in specimens grown in tyrphostin $25 \mu \mathrm{M}$, whereas EGF $10 \mathrm{ng} / \mathrm{mL}$ increased the colonic goblet cell index (number of goblet cells/total colonic epithelial cells) by 1.8-fold compared with controls (Fig. 2, $L$ and $M$, and $5 A$; photo for DMSO control not shown).

EGF and tyrphostin altered epithelial proliferative patterns in the proximal small intestine during organ culture of E12 mouse gut. Exogenous EGF caused the proximal small intestinal epithelium of cultured E12 mouse gut to develop a more mature proliferative pattern with focal localization of proliferative epithelial cells to the intervillus crypt regions by $4 \mathrm{~d}$ of organ culture (Fig. 2, $F$ and $G$ ). Conversely, specimens that were cultured in tyrphostin exhibited a less mature epithelial proliferative pattern in the corresponding regions with larger numbers of proliferative cells that showed no specific pattern of localization along the eventual crypt-villus axis even after $6 \mathrm{~d}$ of culture (Fig. 2, $J$ and $K$ ). The crypt/villus ratio of PCNA indices $($ PCNA index = PCNA-positive cells/total cells) was 3 -fold higher in specimens that were grown in EGF $10 \mathrm{ng} / \mathrm{mL}$ versus tyrphostin $25 \mu \mathrm{M}$ (Fig. 5B). 

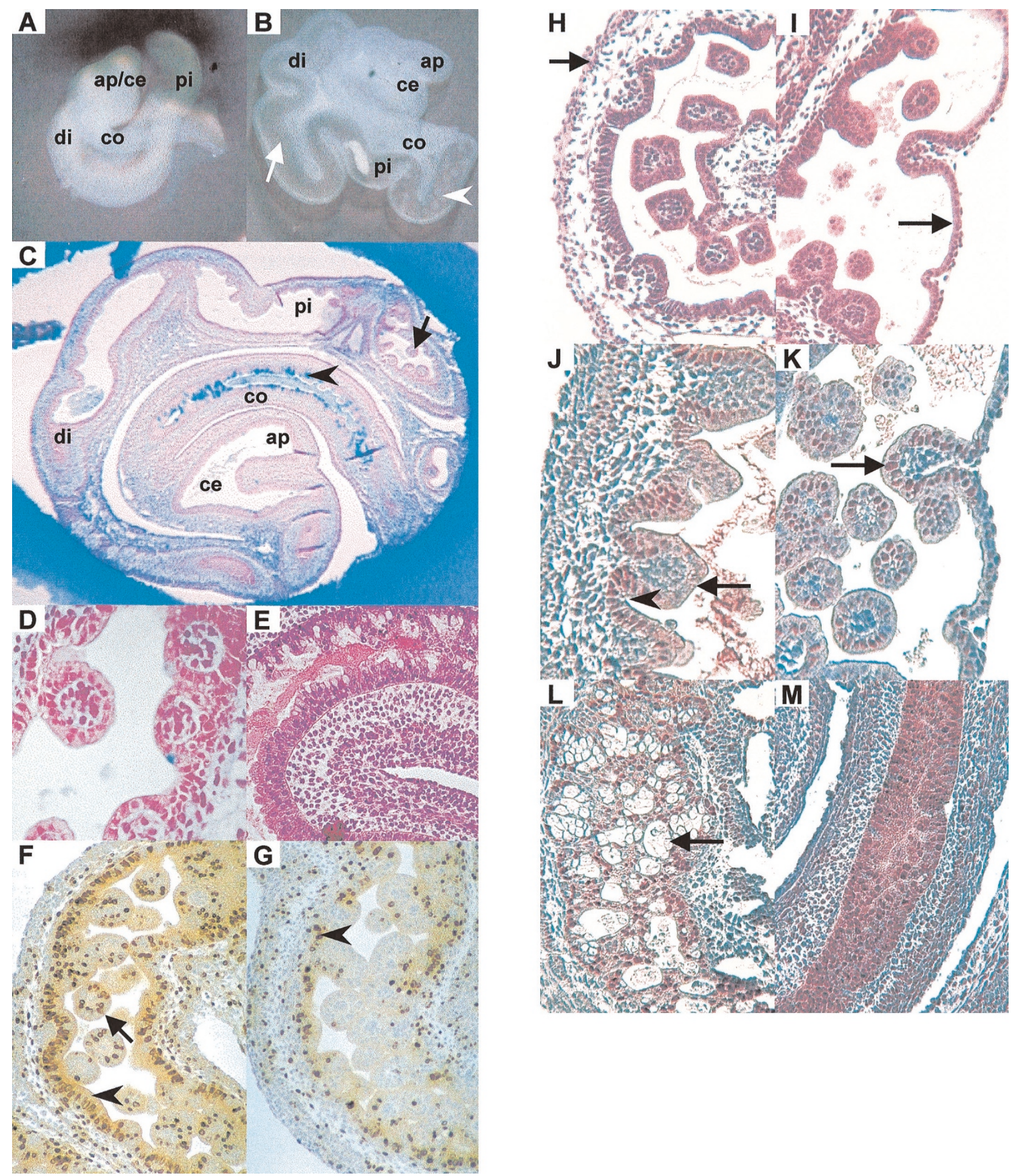

Figure 2. Development of E12 mouse gut in organ culture was regionally specific $(A-E)$ and was affected by exogenous EGF and tyrphostin $(F-M)$. $(A)$ Dissected E12 mouse gut. Ap indicates appendix; ce, cecum; co, colon; di, distal small intestine; pi, proximal small intestine. (B) The same specimen after 6 d of organ culture. Notice the length growth, villus-like structures (arrowhead), and the fluid-filled intestinal lumen (arrow). (C) Regionally distinct histologic features of E12 mouse gut cultured for $6 \mathrm{~d}$ (alcian blue/fast nuclear red). Note the intestinal villiform structures (arrow) and the alcian blue-positive colonic goblet cells (arrowhead). (D) Villiform structures in the proximal small intestine (E12 $+6 \mathrm{~d}$, alcian blue/nuclear fast red). (E) Clear mucus-containing colonic cells $(\mathrm{E} 12+6 \mathrm{~d}, \mathrm{H} \& \mathrm{E}) .(F)$ and $(G)$ Effects of exogenous EGF on intestinal epithelial proliferation $(\mathrm{E} 12+4 \mathrm{~d}$, BrdU immunostaining). The control specimen $(F)$ had abundant BrdU incorporation at the villus base and intervillus regions (arrowhead) but also within the villus epithelium (arrow). This contrasts with ( $G$ ), which was grown in $10 \mathrm{ng} / \mathrm{mL}$ of EGF. Note the more mature appearing villus structures and the restriction of proliferative activity to the nonvillus regions (arrowhead). (H-M) Developmental characteristics of E12 gut cultured for $6 \mathrm{~d}$ with EGF $10 \mathrm{ng} / \mathrm{mL}(H, J, L) v s$ tyrphostin $25 \mu \mathrm{M}(I, K, M)[(H, I) \mathrm{H} \& \mathrm{E} ;(J$, $K)$ PCNA immunostaining, proximal small intestine; and $(L, M)$ PCNA immunostaining, colon]. Specimens grown in EGF had well-formed subepithelial stromal and smooth muscle layers [arrow, $(H)$ ], abundant PCNA expression (brown signal) at the villus base and intervillus regions [arrowhead, $(J)$ ] but not at the villus tips $[$ arrow, $(J)]$, as well as abundant goblet cells [arrow, $(L)]$ and PCNA expression. In contrast, tyrphostin-treated gut had large areas with virtually naked epithelium [arrow, $(I)]$, persistence of PCNA expression in the small intestinal villi [compare arrows in $(J)$ and $(K)$ ], and absence of goblet cells $(M)$. 
A
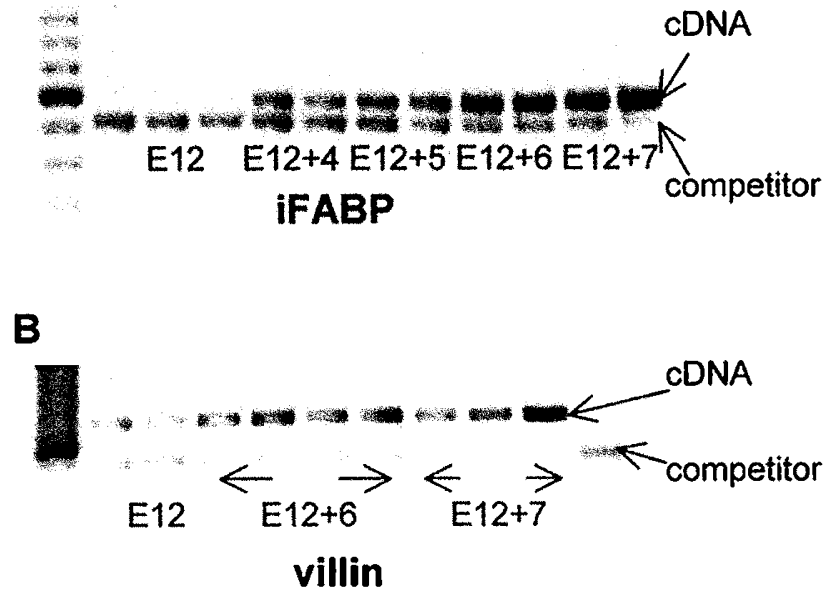

C

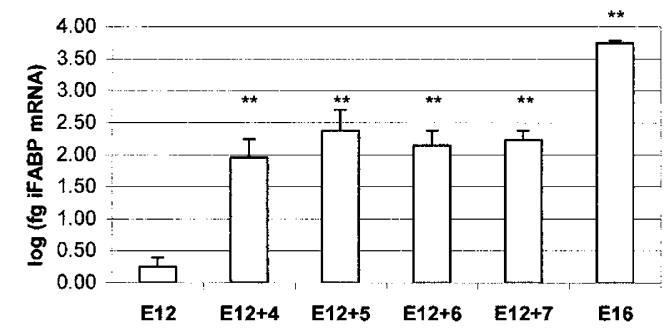

D

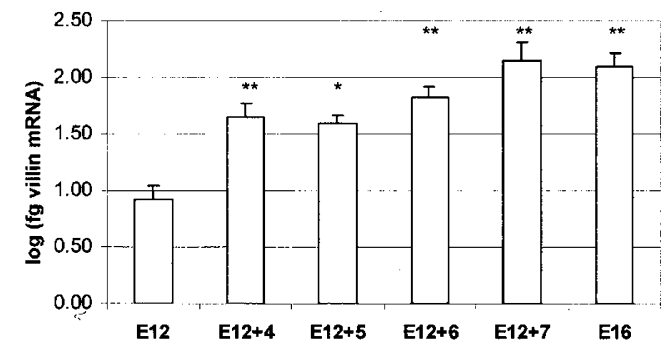

$\mathbf{E}$
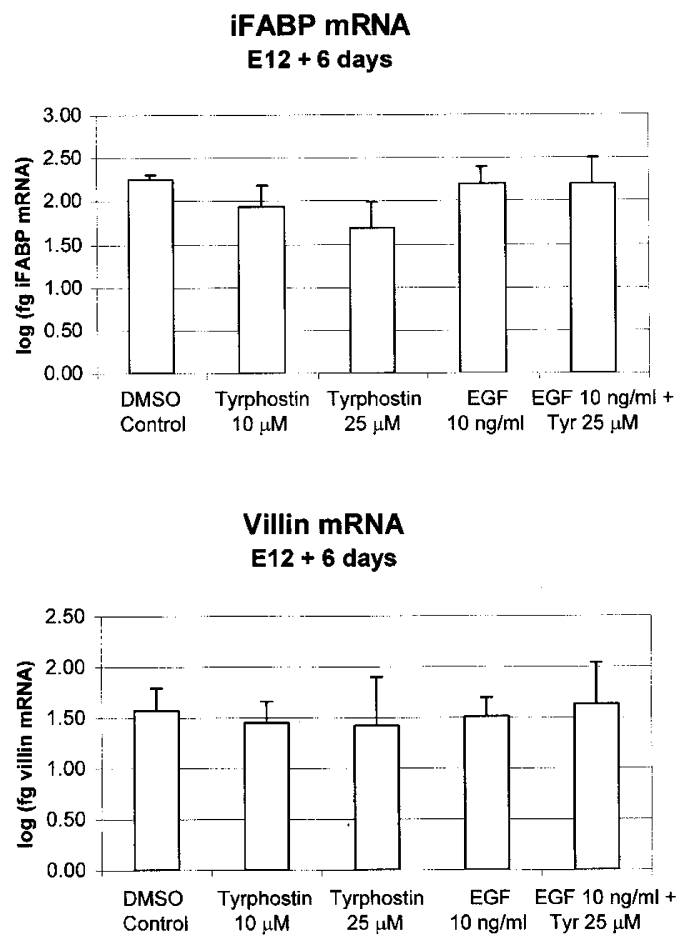

Figure 3. $\mathrm{iFABP}$ and villin mRNA expression in E12 mouse gut increased during organ culture. Competitive PCR for iFABP $(A)$ and villin $(B)$ was performed on standardized reverse-transcribed cDNA from E12 gut cultured for 0 to $7 \mathrm{~d}$ and from intestinal segments of E16 gut for comparison. mRNA quantities $(C)$ and $(D)$ are expressed as logarithmically transformed values (fg) $+/$ - SEM, and paired comparisons are performed with $\mathrm{d} 0 . *^{*} p<0.01 ; * * p<0.001$. Exogenous EGF and tyrphostin did not significantly affect $\operatorname{iFABP}(E)$ or villin $(F)$ mRNA expression in E12 gut cultured for $6 \mathrm{~d}$.

\section{DISCUSSION}

The results of the present study indicate that EGFR signaling has an important function in regulating early embryonic gut crypt/villus axis and goblet cell maturation during organ culture. Developmentally, E12 mouse gut is just initiating midgut rotation and is similar to that of a midfirst trimester human embryo (26). Nutrient and oxygen diffusion in this model appears to be sufficient, because cytotoxic changes were not apparent during culture and the most intensely proliferative regions appeared to be in the cecum/appendix and colon, which have the greatest wall thickness. Although most gut organ cultures were previously performed with $95 \% \mathrm{O}_{2}$ and $5 \% \mathrm{CO}_{2}$, we used $95 \%$ air and $5 \% \mathrm{CO}_{2}$, which have become wellestablished for culturing embryonic mouse organs that include the lung, mandible, limb buds, and stomach $(15,24,27,28)$. This also avoids the possibility of hyperoxic tissue injury. The simultaneous culture of the small intestine and colon is a novel feature in this model, which permits studying in vitro gut development along the anteroposterior axis. The duodenum was not cultured because of its proximity to the developing pancreas, which may produce chemical factors that affect embryonic gut growth and development. 


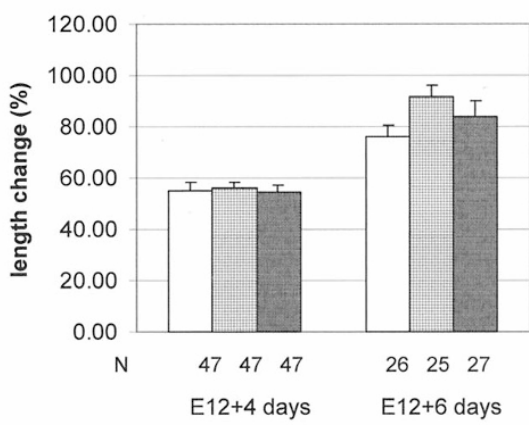

$\square$ Control $\square E G F 1 \mathrm{ng} / \mathrm{ml}$ $\square E G F 10 \mathrm{ng} / \mathrm{ml}$

B

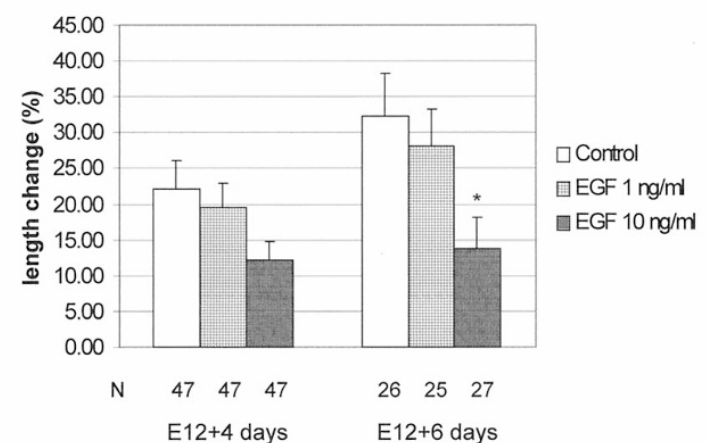

C

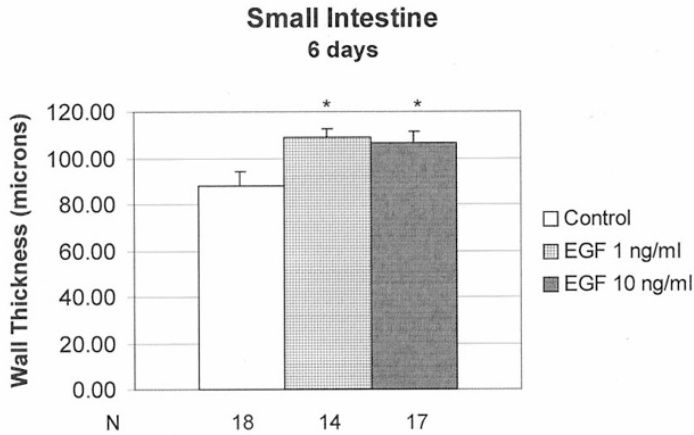

D

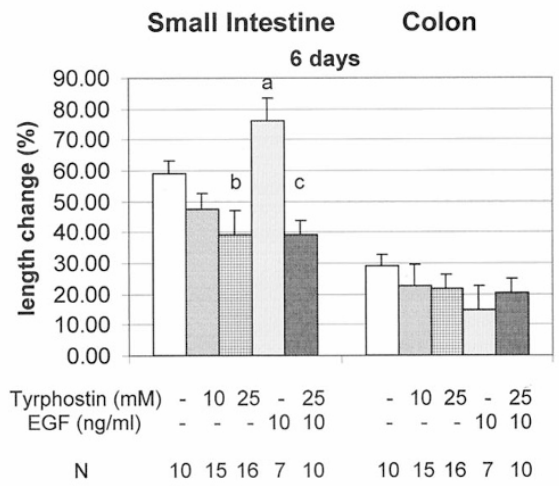

Figure 4. EGF and tyrphostin altered in vitro growth patterns of E12 mouse gut. (A) Exogenous EGF did not significantly affect small intestine lengthening during organ culture. Conversely, culture with EGF $10 \mathrm{ng} / \mathrm{mL}$ resulted in an inhibition of colon length growth $(B)$. $(C)$ EGF increased small intestinal wall thickness during organ culture. Results for $(A)$ through $(C)$ are shown as \% length change $+/$ - SEM, and paired comparisons are with the control group. ${ }^{*} p$ $<0.05$. (D) Small intestinal length growth of E12 mouse gut specimens that were cultured with EGF $10 \mathrm{ng} / \mathrm{mL}$ was significantly greater than those that were grown in tyrphostin $25 \mu \mathrm{M}$. Results are shown as \% length change $+/$ SEM. Tukey-Kramer $p$ value between $(A)$ and $(B)<0.01$; between $(A)$ and $(C)$ $<0.05 . p$ (ANOVA) $<0.05$ for $(B),(C)$, and $(D)$.
A

Goblet Cells - Colon

6 days

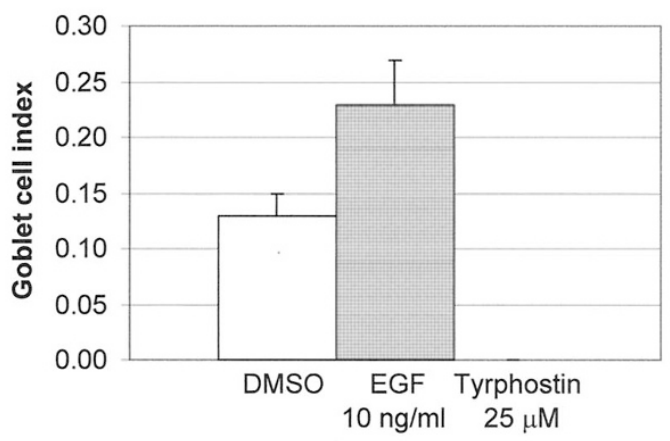

B
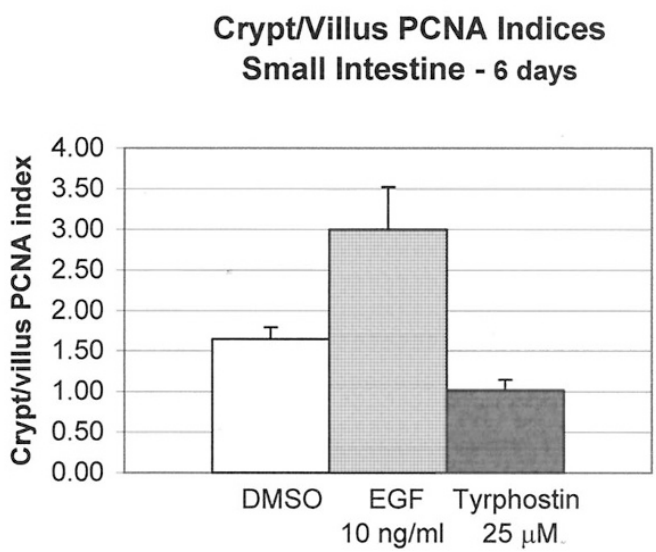

Figure 5. Effects of EGF and tyrphostin on goblet cell development and maturation of the differential crypt/villus proliferative pattern. (A) Colonic goblet cells were absent in E12 mouse gut grown in tyrphostin $25 \mu \mathrm{M}$ for $6 \mathrm{~d}$ and increased in specimens grown in EGF $10 \mathrm{ng} / \mathrm{mL}$ compared with controls. (Goblet cell index $=$ number of goblet cells/total number of colonic epithelial cells.) $(B)$ The crypt/villus ratio of PCNA indices (PCNA index = PCNApositive cells/total cells) were increased by EGF $10 \mathrm{ng} / \mathrm{mL}$ and decreased by tyrphostin $25 \mu \mathrm{M} . n=5$ per group for both $(A)$ and $(B)$. Results are shown as mean values +/- SEM. $p<0.05$ for all paired comparisons.

E12 mouse gut in organ culture showed many developmental similarities to those grown in vivo. Early intestinal villus and colonic goblet cell development in vitro indicates an anteroposterior pattern of regionally specific epithelial differentiation. Moreover, the clustering of proliferative epithelial cells to intervillus crypt regions in the proximal small intestine during organ culture simulates normal gut maturation in which the intestinal epithelium organizes into proliferative crypt regions and terminally differentiated villi (26). Finally, the increased iFABP and villin mRNA expression during organ culture as detected by RT/competitive PCR was similar to their expression during in vivo embryonic gut development. iFABP (29), a cytoplasmic protein involved in intracellular long-chain fatty acid transport, and villin (30), a brush-border intermediate filament, were chosen as candidate markers of intestinal epithelial differentiation because both are known to have increased expression before the period of endodermal-villus transition. Assays were performed on total RNA from whole cultured tissue due to their small size, which yielded an average of only $2 \mu \mathrm{g}$ of total RNA per specimen. It is not clear 
whether the reduced iFABP levels in organ culture relative to in vivo was due to decreased gut expression in vitro or whether a regionally restricted iFABP expression pattern was present during organ culture. In addition, it is somewhat unexpected to find a lack of significant effect by EGF or tyrphostin on either villin or iFABP mRNA expression during organ culture. Although results from this study suggest that EGF does not affect villin and iFABP mRNA expression during development, it is possible that EGF may differentially regulate their expression in distinct gut anatomic regions and that such effects are not detectable in mRNA obtained from whole homogenized cultured tissue. Regional mRNA expression patterns of villin and iFABP will be further investigated by in situ hybridization.

The growth of E12 mouse gut during organ culture was decreased compared with in vivo. A slower growth rate is expected in chemically defined organ culture because it is an unperfused and serumless model, with intentional deprivation of exogenous serum and maternal factors, to study the endogenous control of embryonic developmental processes. Such stringent limitations in the nutritional and chemical environment may also have limited early villus development in vitro to the proximal small intestine. Because embryonic gut normally develops in a cranial to caudal direction (26), we speculate that villus morphogenesis in the distal small intestine may require specific molecular signals that were not present endogenously at E12. Specific factors that regulate villus morphogenesis have not yet been identified; however, genes that play roles in longitudinal axis determination such as the homeobox genes and genes involved in caudal and fibroblast growth factor signaling appear to be likely candidates at this time (31).

We have shown that exogenous EGF produces a complex pattern of in vitro growth effects on E12 mouse gut. The effects are regionally distinct, as EGF 1 and $10 \mathrm{ng} / \mathrm{mL}$ did not affect small intestinal length growth, whereas EGF $10 \mathrm{ng} / \mathrm{mL}$ decreased colonic lengthening. A plausible explanation of why EGF $10 \mathrm{ng} / \mathrm{mL}$ did not result in greater increases in small intestinal lengths is that higher EGF concentrations may actually inhibit length growth via down-regulation of EGFR signaling mechanisms. Although we have not directly demonstrated how exogenous EGF has access to its cognate receptor on the intestinal epithelium, the observed biologic effects of exogenous EGF on E12 mouse gut growth and development indicate that significant receptor-ligand interactions had occurred. We have also shown that EGFR mRNA expression in E12 mouse gut is down-regulated by exogenous EGF during organ culture (data not shown). This is reassuring because EGFR in the mouse gut is expressed on the basolateral epithelium $(8,17,32)$, in contrast with the piglet jejunum in which EGFR is found on both the apical and basolateral epithelial surface (33).

In addition, the effects of EGFR signaling on embryonic gut lengthening may occur secondarily to its effects on gut epithelial proliferation and maturation. Our organ culture studies showed that proliferative intestinal epithelial cells become localized to the intervillus regions as the crypt-villus axis is being formed. This maturational organization of the small intestinal epithelium appears to be accelerated by EGF and delayed by tyrphostin. This suggests that higher EGF concen- trations may paradoxically reduce gut length by causing accelerated gut epithelial maturation during periods that are critical for normal gut lengthening. This speculation is consistent with the report of longer intestinal lengths measured in the waved-2 mouse (34), which has a defective EGFR tyrosine kinase (35), and that of shorter intestinal lengths in transgenic mice with targeted intestinal overexpression of EGF (36).

It is not clear why tyrphostin $25 \mu \mathrm{M}$ caused intestinal wall defects that were concentrated over the antimesenteric small intestinal wall. Although penetration of tyrphostin through all cell layers was not specifically demonstrated in this study, effective dose-dependent inhibition of EGF-stimulated tyrosine phosphorylation by the tyrphostin RG50864 has been reported in organ cultures of other organs $(24,28)$. Relatively low tyrphostin concentrations (less than twice the $\mathrm{IC}_{50}$ ) were used in this study to minimize potential nonspecific cytotoxic effects by tyrphostin and the DMSO solvent. Incomplete EGFR inhibition may, therefore, account for the partial reversal of the intestinal wall defects by exogenous EGF. However, this suggests the assertion that the defects were due to specific effects of tyrphostin on EGFR signaling rather than nonspecific cytotoxic phenomena.

In addition to showing the effects of EGF on the maturation of the small intestinal crypt/villus axis, our studies also indicated that EGFR signaling plays an important role in colonic goblet cell maturation. Goblet cells were increased by 1.8 -fold versus control after $6 \mathrm{~d}$ of organ culture in E12 mouse gut cultured with exogenous EGF and were completely absent in guts that were cultured with tyrphostin. Miettinen et al. (1) have reported that $\mathrm{EGFR}^{-/-}$mice have normal-appearing goblet cells at birth . Our findings were consistent with earlier reports that EGF markedly up-regulates mucus glycoprotein production in human stomachs as early as 12 to $20 \mathrm{wk}$ of gestation $(15,37)$. EGF has also been shown to protect rats against experimental chemical colitis, and the probable role of stimulated goblet cell function by EGF in such a model has been discussed previously (38).

To summarize, we have demonstrated by using exogenous EGF and tyrphostin in a chemically defined organ culture model of E12 mouse gut that EGFR signaling regulates embryonic gut growth as well as the maturation of the intestinal crypt/villus axis and colonic goblet cells. These further insights on how EGFR signaling mechanisms regulate gut maturation may potentially lead to novel therapeutic approaches in the management of necrotizing enterocolitis and other intestinal disorders that affect the severely premature infant.

Acknowledgments. The authors thank Pablo Bringas, Jr., Valentino Santos, Dr. Guillermo Flores-Delgado, and Dr. Jingsong Zhao at the Center for Craniofacial Molecular Biology (CCMB), University of Southern California School of Dentistry for technical advice. Dr. Zhao also generously supplied the $\beta$-actin competitor and primers for competitive PCR.

\section{REFERENCES}

1. Miettinen PJ, Berger JE, Meneses J, Phung Y, Pedersen RA, Werb Z, Derynck R 1995 Epithelial immaturity and multiorgan failure in mice lacking epidermal growth factor receptor. Nature 376:337-341 
2. Kliegman RM, Fanaroff AA 1981 Neonatal necrotizing enterocolitis: a nine-year experience. Am J Dis Child 135:603-607

3. Pollack PF, Goda T, Colony PC, Edmond J, Thornburg W, Korc M, Koldovsky O 1987 Effects of enterally fed epidermal growth factor on the small and large intestine of the suckling rat. Regul Pept 17:121-132

4. Foltzer-Jourdainne C, Garaud JC, Nsi-Emvo E, Raul F 1993 Epidermal growth factor and the maturation of intestinal sucrase in suckling rats. Am J Physiol 265:G459G466

5. Emvo EN, Raul F, Koch B, Neuville P, Foltzer-Jourdainne C 1996 Sucraseisomaltase gene expression in suckling rat intestine: hormonal, dietary, and growth factor control. J Pediatr Gastroenterol Nutr 23:262-269

6. Threadgill DW, Dlugosz AA, Hansen LA, Tennenbaum T, Lichti U, Yee D, LaMantia C, Mourton T, Herrup K, Harris RC, Barnard JA, Yuspa SH, Coffey RJ, Magnuson T 1995 Targeted disruption of mouse EGF receptor: effect of genetic background on mutant phenotype. Science 269:230-234

7. Hormi K, Lehy T 1994 Developmental expression of transforming growth factoralpha and epidermal growth factor receptor proteins in the human pancreas and digestive tract. Cell Tissue Res 278:439-450

8. Chailler P, Ménard D 1999 Ontogeny of EGF receptors in the human gut. Front Biosci 4:D87-D101

9. Beaulieu JF, Ménard D, Calvert R 1985 Influence of epidermal growth factor on the maturation of the fetal mouse duodenum in organ culture. J Pediatr Gastroenterol Nutr $3: 476-481$

10. Menard D, Arsenault P, Gallo-Payet N 1986 Epidermal growth factor does not act as a primary cue for inducing developmental changes in suckling mouse jejunum. J Pediatr Gastroenterol Nutr 5:949-955

11. Beaulieu JF, Calvert R 1981 The effect of epidermal growth factor (EGF) on the differentiation of the rough endoplasmic reticulum in fetal mouse small intestine in organ culture. J Histochem Cytochem 29:765-770

12. Conteas CN, DeMorrow JM, Majumdar AP 1986 Effect of epidermal growth factor on growth and maturation of fetal and neonatal rat small intestine in organ culture. Experientia 42:950-952

13. Ménard D, Arsenault P, Pothier P 1988 Biologic effects of epidermal growth factor in human fetal jejunum. Gastroenterology 94:656-663

14. Ménard D, Corriveau L, Arsenault P 1990 Differential effects of epidermal growth factor and hydrocortisone in human fetal colon. J Pediatr Gastroenterol Nutr 10:13-20

15. Tremblay E, Monfils S, Menard D 1997 Epidermal growth factor influences cell proliferation, glycoproteins, and lipase activity in human fetal stomach. Gastroenterology 112:1188-1196

16. Goodlad RA, Wright NA 1996 Epidermal growth factor (EGF). Baillieres Clin Gastroenterol 10:33-47

17. Barnard JA, Beauchamp RD, Russell WE, Dubois RN, Coffey RJ 1995 Epidermal growth factor-related peptides and their relevance to gastrointestinal pathophysiology. Gastroenterology 108:564-580

18. Uribe JM, Barrett KE 1997 Nonmitogenic actions of growth factors: an integrated view of their role in intestinal physiology and pathophysiology. Gastroenterology 112:255-268

19. Beardmore JM, Richards RC 1983 Concentrations of epidermal growth factor in mouse milk throughout lactation. J Endocrinol 96:287-292

20. Hofmann GE, Abramowicz JS 1990 Epidermal growth factor (EGF) concentrations in amniotic fluid and maternal urine during pregnancy. Acta Obstet Gynecol Scand 69:217-221
21. Popliker M, Shatz A, Avivi A, Ullrich A, Schlessinger J, Webb CG 1987 Onset of endogenous synthesis of epidermal growth factor in neonatal mice. Dev Biol 119:38-44

22. Gazit A, Yaish P, Gilon C, Levitzki A 1989 Tyrphostins I: synthesis and biological activity of protein tyrosine kinase inhibitors. J Med Chem 32:2344-2352

23. Theiler K 1989 The House Mouse. Springer-Verlag, New York, pp 87-93

24. Warburton D, Seth R, Shum L, Horcher PG, Hall FL, Werb Z, Slavkin HC 1992 Epigenetic role of epidermal growth factor expression and signaling in embryonic mouse lung morphogenesis. Dev Biol 149:123-133

25. Zhao J, Nishimoto SK 1995 An RNA-competitive polymerase chain reaction method for human matrix gamma-carboxyglutamic acid protein mRNA measurement. Anal Biochem 228:162-164

26. Weaver LT 1996 Anatomy and embryology. In: Walker WA, Durie PR, Hamilton JR, Walker-Smith JA, Watkins JB (eds) Pediatric Gastrointestinal Disease: Pathophysiology, Diagnosis, Management. Mosby-Year Book, St. Louis, pp 9-30

27. Chai Y, Bringas Jr P, Shuler C, Devaney E, Grosschedl R, Slavkin HC 1998 A mouse mandibular culture model permits the study of neural crest cell migration and tooth development. Int J Dev Biol 42:87-94

28. Canoun C, Ma C, Halpern D, Shum L, Bringas Jr P, Sank A, Slavkin HC 1993 Endogenous epidermal growth factor regulates limb development. J Surg Res 54:638-647

29. Green RP, Cohn SM, Sacchettini JC, Jackson KE, Gordon JI 1992 The mouse intestinal fatty acid binding protein gene: nucleotide sequence, pattern of developmental and regional expression, and proposed structure of its protein product. DNA Cell Biol 11:31-41

30. Maunoury R, Robine S, Pringault E, Huet C, Guenet JL, Gaillard JA, Louvard D 1988 Villin expression in the visceral endoderm and in the gut anlage during early mouse embryogenesis. EMBO J 7:3321-3329

31. Isaacs HV, Pownall ME, Slack JMW 1998 Regulation of Hox gene expression and posterior development by the Xenopus caudal homologue Xcad3. EMBO J 17:34133427

32. Scheving LA, Shiurba RA, Nguyen TD, Gray GM 1989 Epidermal growth factor receptor of the intestinal enterocyte. Localization to laterobasal but not brush border membrane. J Biol Chem 264:1735-1741

33. Kelly D, McFadyen M, King TP, Morgan PJ 1992 Characterization and autoradiographic localization of the epidermal growth factor receptor in the jejunum of neonatal and weaned pigs. Reprod Fertil Dev 4:183-191

34. Hemlrath MA, Erwin CR, Warner BW 1997 A defective EGF-receptor in waved-2 mice attenuates intestinal adaptation. J Surg Res 69:76-80

35. Luetteke NC, Phillips HK, Qiu TH, Copeland NG, Earp HS, Jenkins NA, Lee DC 1994 The mouse waved-2 phenotype results from a point mutation in the EGF receptor tyrosine kinase. Genes Dev 8:399-413

36. Erwin CR, Helmrath MA, Shin CE, Falcone RA, Stern LE, Warner BW 1999 Intestinal overexpression of EGF in transgenic mice enhances adaptation after small bowel resection. Am J Physiol 277:G533-G540

37. Kelly SM, Hunter JO 1990 Epidermal growth factor stimulates synthesis and secretion of mucus glycoproteins in human gastric mucosa. Clin Sci (Colch) 79:425-427

38. Procaccino F, Reinshagen M, Hoffmann P, Zeeh JM, Lakshmanan J, McRoberts JA, Patel A, French S, Eysselein VE 1994 Protective effect of epidermal growth factor in an experimental model of colitis in rats. Gastroenterology 107:12-17 